limited by the length of this suitable period, by the labour and equipment available for the job, and by the technique used for the operation. For a given size of farm with normal staff and equipment, the optimum area of crop will be limited by the probability of getting the necessary weather sequence and by the harvesting technique. For hay, eastern England can count on a long sequence of good haymaking days, so the technique used there may not be equally successful in the south-west with its higher and more frequent rainfall; the most effective technique for the south-west would be one making some allowance for the climate of the region.

A further general topic led Mr. Gloyne to a point of particular interest. As is well known, dusting and spraying techniques against insect attack and plant pathogens are, like the spreading of some fertilizers, at the mercy of the wind. The wind-speed above which control becomes very difficult varies with particle-size and spreading technique; but it is usually a long way below gale force, and for finer materials may be only a few miles an hour. When the material is suspended or dissolved in water, high-pressure spraying is usually successful; but there are areas so short of water that it must be applied as a dust, and the problem arises of finding some means of making the dust stick to the plants. A heavy dew deposit will serve, and Mr. Gloyne had been asked if it would be possible to get forecasts of occasions on which early mornings of heavy dew would be followed by conditions calm enough for dusting operations to be carried out without undue loss by blowing away.

Mr. Gloyne's final remarks would be broadly accepted by most present : meteorology should be more concerned with growing food and less with getting an aeroplane from place $A$ to place $B$; and an early resumption of the discussion was highly desirable.

H. L. P. $3 \| 6$

\section{NUTRITION AND FERTILITY}

$\mathrm{T}$ HE War accenthated the difficulties of food production and the maintenance of an adequate diet for humandise. Actual destruction and the diversion of humar ctivity to destructive aims, mass mot menter the population to avoid or assist mithy.operatchs, and the natural increase of the poplation, which in spite of these disturbances continued with very little check, have brought peace-time problems of great urgency : how to maintain or raise the standard of nutrition, and at the same time make provision for the increasing population or alternatively how to control the rate of increase. Nutrition and fertility are therefore socially and economically related as well as causally connected. The emphasis of the Conference held by the Nutrition Society on March 5 was on the causal connexions, but many experiences were drawn from the social and economic spheres. Thus, Dr. G. I. M. Swyer directed attention to the apparent paradox that in the East (China, India, etc.) a high birth-rate and expanding population is associated with poverty and under-nourishment, whereas in the West adequate nourishment is associated with a stationary or declining population. Prof. A. St. G. Huggett, on the other hand, instanced the effects of starvation or near starvation on the depression of the conceptual-rate, birth-rate and birthweight, and increase in abortion-rate and prematurity. rate, in the populations of Stalingrad and Holland during the worst periods of the War. Dr. J. Edwards showed that data collected from animal artificial insemination centres primarily concerned with increasing the milk production could be analysed to give valuable information on the effect of seasonal nutrition on bovine fertility. Dr. J. Hammond and Dr. S. J. Folley both drew inferences on the effects of nutrition on fertility from agricultural practice, and Prof. Huggett and Dr. Swyer from clinical medicine.

This approach to the subject from a wide field of generalizations necessarily brought to light the existing lack of exact knowledge on many subjects, which was particularly evident in the case of nutritional therapy. The Conference succeeded, however, not only in directing attention to gaps in our knowledge but also summarized much original and recent research.

Dr. J. Hammond, in his paper on "The Physiology of Reproduction in Relation to Nutrition", gave a very broad review. The onset of puberty is determined by factors outside the gonads; immature ovaries implanted into adult animals function immediately; mature ovaries implanted into immature animals do not function until puberty is reached. The activity of the gonad and body-growth are determined by the hormones of the anterior pituitary, and normally the onset of puberty occurs as the adult growth-rate diminishes, so that the onset of puberty must depend upon a balance of output between the growth hormone and the gonadotrophic hormones. A very high plane of nutrition may reduce the time of onset of puberty, but the weight of the animal at puberty is increased. In the mammal this may be a disadvantage by causing a diversion of nutrients from the embryo and mammary gland to the body tissues. Conversely, poor nutrition leads to delay in the age of puberty, but puberty occurs at a lower body-weight than normal. In this case pregnancy and lactation place a considerable burden on the undergrown mother. Good nutrition increases the number of ova shed. The number of ova fertilized may depend upon the viability of the spermatozoa, and there is some evidence that this is affected by the nutritional condition of the male. Development of the sheep embryo during gestation is affected by the plane of nutrition. The birth-weight and viability of lambs born to ewes underfed during the later stages of pregnancy may be seriously affected and subsequent growth retarded by deficient lactation.

Dr. A. Walton, speaking on "Spermatogenesis and Nutrition", gave an estimate of seminal output in the male and showed how this is related to the total metabolic activity of the testes. The total weekly output of semen even during great sexual activity is extremely small and cannot be regarded as a serious drain on the nutritional requirements. The spermatozoon is a highly differentiated cell in some respects, but genetic argument leads to the conclusion that the nucleus contains half the genes which are common to the somatic cells. The locomotory apparatus and metabolism are similar in most respects to muscle.

Dr. J. Edwards, on "Variations in Fertility Levels in Bovines", analysed data from insemination centres to show that although cows are fed very differently during winter and summer, the conception-rate is not significantly affected. Contrary to common expectation, the lowest rate is found to be in the quarter of the year from April to June. Bulls show no striking effects of nutrition on semen output. Dr. 
S. J. Folley, on "Nutrition and Female Fertility", dealt more specifically with the causal mechanisms of nutrition. Since reproductive activity is largely controlled through endocrine mechanisms, it is to be expected that nutritional effects will act through the endocrine glands. Evidence that anterior pituitary activity is affected by nutritional factors is available. For example, rats on a restrictive diet show no œstrous cycles, but respond to injections of gonadotrophic hormones. Atrophied accessory sex organs of rats on a diet deficient in B vitamins may be restored by injection of gonadotrophic hormones. Lowered pituitary function due to inadequate nutrition may be the cause of anœstrus during winter in heifers. A direct effect of nutrition on the ovary is not established, but since the œstrogen-level in the body is due to the balance between production by the ovary and excretion, deficiencies in the excretory mechanism may lead to syndromes similar to those set up by excess cestrogen activity in the ovary. B-deficiency (thiamin and riboflavin) and diets low in lipotrophic factors may affect the efficiency of the liver to inactivate œestrogens and lead to syndromes relating to sterility, such as pathological uterine bleeding. Evidence that nutritional factors may affect the responsiveness of the tract to œestrogens is provided by Herz, who found that the oviduct of chicks fed on diets deficient in folic acid did not respond to œestrogens ; $20 \mu \mathrm{gm}$. of folic acid daily restored normal responsiveness. Some analogous results have been found in mammals.

Prof. A. St. G. Huggett, on "Nutrition and Viable Young", dealt in detail with a more limited aspect of nutritional deficiency, namely, the placental life of the embryo. Vitamin A deficiency results in a generalized metaplasia of epithelial surfaces. In the rat there is continuous keratinization of the vagina. Usually the foetus goes to term but dies because the birth mechanism is upset. In severe cases, however, placental death and fœtal absorption may occur. Vitamin $\mathrm{E}$ deficiency has no action on rats before the eighth day from copulation, that is, three days after implantation. There are parallels between the action of $\mathrm{E}$ deficiency and experimental embryonic trauma. In both cases changes in the placenta result from destruction of the mesoderm tissues and allantoic blood flow. The foetus is resorbed, but the tropho. blastic placenta stays in position and is delivered at term. Apparently vitamin A deficiency kills the fotus as a secondary effect of placental death, whereas vitamin $\mathrm{E}$ deficiency acts mainly on fœtal hæmatopoietic organs and leaves the decidua and trophoblast intact. Riboflavin deficiency in rats may result in many congenital deformities, but this effect only occurs during the early stages of pregnancy when apparently riboflavin is essential to early ossification. An interesting parallel occurs with rubella infection, which may result in congenital cataract or heart lesions if the mother is infected in the second month of pregnancy.

Dr. G. I. M. Swyer, who discussed "Nutrition and Human Fertility", was concerned mainly with clinical diagnosis and therapy. Gross under-nourishment results in amenorrhoea and menstrual disorders and a fall in conception-rate. Over-nourishment and obesity are commonly associated with infertility in women. Recent observations by Barton and Wiesner on refractory cervical block, which is common in sterile obese women, show that the condition responds with marked success to a dietary free from sugar. The precise way in which dietary sugar brings about the syndrome of obesity, genital infection and refractoriness to œstrogens is still obscure. Successful treatment of infertility with vitamin $\mathrm{E}$ has been much advertised. For the male the evidence is mostly negative or statistically inconclusive. For women there is evidence that habitual abortion may bo successfully treated with. vitamin E.

Arthur Watton

\section{OBITUARIES $10 \%$ \\ Dr. A. Cunningham}

By the death of Dr. Andrew Cunningham in Edinburgh on Mgrth 4, agricultural bacteriology has lost an outstgling figure. The son of a farmer, Cunninghary ras born near Glenfarg on August 26, 1890. Fom chool at Perth Academy he proceeded in 1908 the University of Edinburgh, and after grofiating in agriculture in 1911 he worked for a year in the chemistry department of the Edinburgh College of Agriculture. Deciding to study bacteriology, he spent the following winter at the Lister Institute and King's College in London, and then proceeded to Leipzig, where he worked for a year under Felix Löhnis. There, his first investigation concerned plate counts of bacteria in soil and milk, and he showed the importance of long incubation at a low temper. ature if maximum counts are to be obtained. In Leipzig, also, he did some of the pioneer work on the Protozoa of soil and their influence on the soil micro. flora. Cunningham's future career seems to have been greatly influenced by Löhnis, and it may be more than coincidence that the two men bore a remarkably strong resemblance in temperament and scientific outlook.

After working for short periods at Berne, Shinfield and Rothamsted, Cunningham joined the army in 1915 and saw active service in France. On demobilization in 1919 he was appointed lecturer in bacteriology at the Edinburgh College of Agriculture. With characteristic energy he overcame the many difficulties of building up from virtually nothing an efficient teaching department. Six years later he exchanged the lectureship for the post of adviser in bacteriology, and he at once entered with enthusiasm into the work that continued until his death. In addition to his advisory duties, Cunningham was able for several years to devote much of his time to purely scientific work on the anaerobes of soil and manures. He found that some of the butyric acid bacilli displayed a life-cycle similar to that described in Azotobacter by Löhnis and Smith. This work, although its findings are still controversial, ranks as the most important in his career, and it provided material for the thesis accepted by the University of Edinburgh for the degree of D.Sc. in 1931.

Cunningham's published work covers a consider. able range of agricultural subjects, including the bacteriology of silage and manures, methods of examining milk, taints in milk, and the inoculation of lucerne. In recent years he had been occupied principally in an investigation of bovine mastitis, where one may easily detect his carefully devised plans, which were carried out with determination and meticulous care. His "Practical Bacteriology for Students of Agriculture", which is now in its third edition, is widely recognized as one of the best books of its kind. Abstract journals appreciated his services 